\title{
Late-diagnosed primary hyperparathyroidism resulting in loss of kidney and advanced osteoporosis
}

Malgorzata Jacewicz, Anna Zielińska, Anna Popławska-Kita, Małgorzata Szelachowska, Maria Górska

Department of Endocrinology, Diabetology and Internal Medicine, Medical University of Białystok, Poland

\section{Introduction}

The report describes the case of a late-diagnosed primary hyperparathyroidism in the patient, who developed severe renal complications and advanced osteoporosis with hungry bone syndrome after removal of parathyroid adenoma.

\section{Case report}

Sixty-three year old woman with long-lasting nephrolithiasis was admitted to the hospital due to high serum PTH concentration detected in a routine laboratory testing. Two years before admission to the hospital she had undergone left-sided nephrectomy because of hydronephrosis. In the last year she lost $5 \mathrm{~kg}$ and suffered from asthenia, joint-pain and recurrent urinary tract infections.



Thyroid gland Tc-99m

\begin{tabular}{|c|c|}
\hline 2070 & $\mathrm{~N}: 15-68,3 \mathrm{pg} / \mathrm{ml}$ \\
\hline 1047 & $\mathrm{~N}: 37-123 \mathrm{IU} / \mathrm{I}$ \\
\hline 3,26 & $\mathrm{~N}: 2,25-2,75 \mathrm{mmol} / \mathrm{l}$ \\
\hline 1,91 & $\mathrm{~N}: 1,1-1,3 \mathrm{mmol} / \mathrm{I}$ \\
\hline 8,8 & $\mathrm{~N}: 12-16 \mathrm{~g} \%$ \\
\hline 2,12 & $\| \mathrm{N}: 0,6-0,9 \mathrm{mg} / \mathrm{dl}$ \\
\hline 19 & $\mathrm{~N}:>90 \mathrm{ml} / \mathrm{min}$ \\
\hline 92,4 & $\mathrm{~N}: 100-300 \mathrm{mg} / 24 \mathrm{~h}$ \\
\hline 367 & $\mathrm{~N}: 600-1200 \mathrm{mg} / 24 \mathrm{~h}$ \\
\hline 11 & $\mathrm{~N}: 30-40 \mathrm{ng} / \mathrm{ml}$ \\
\hline
\end{tabular}

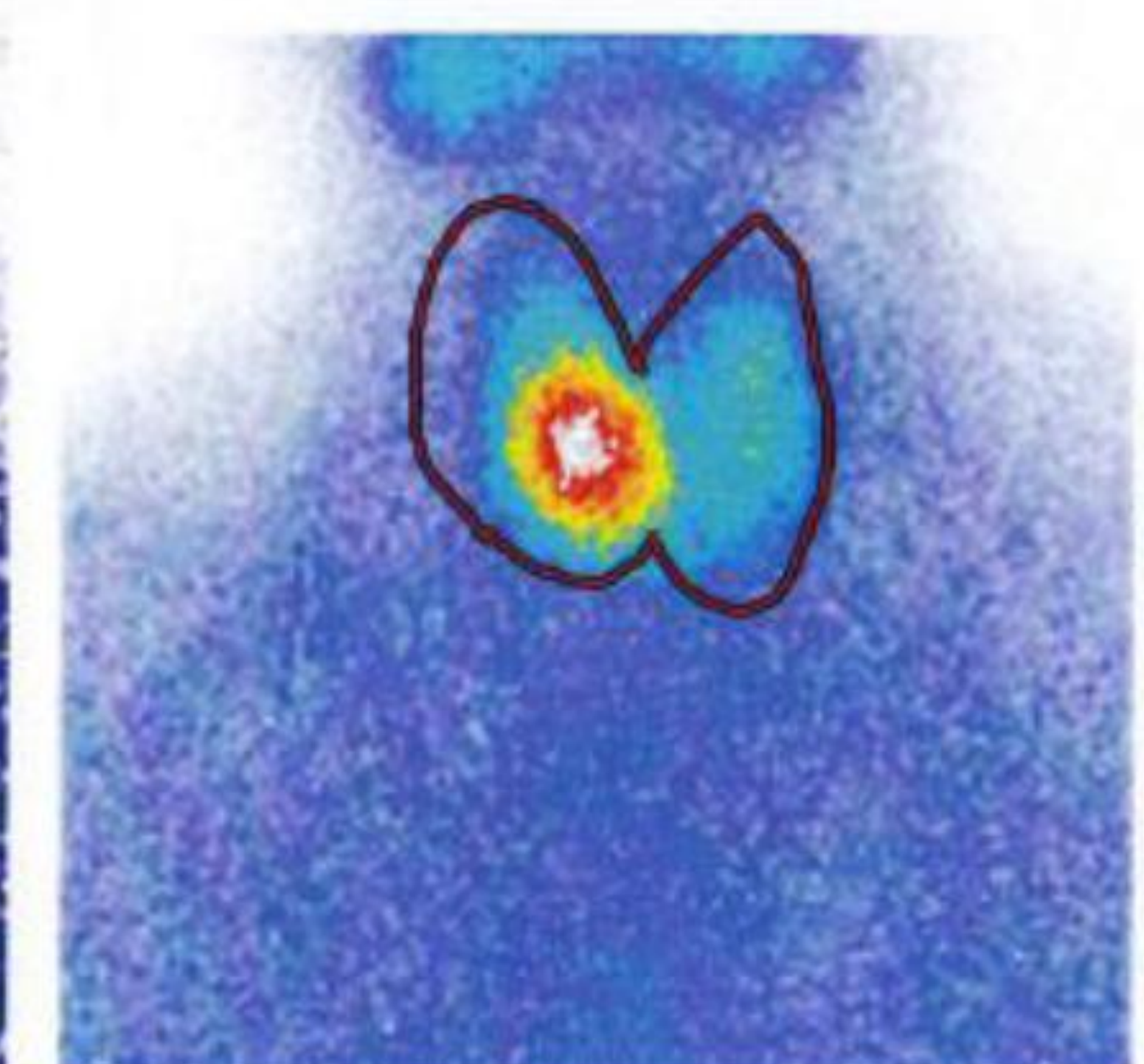

Parathyroid glands MIBI
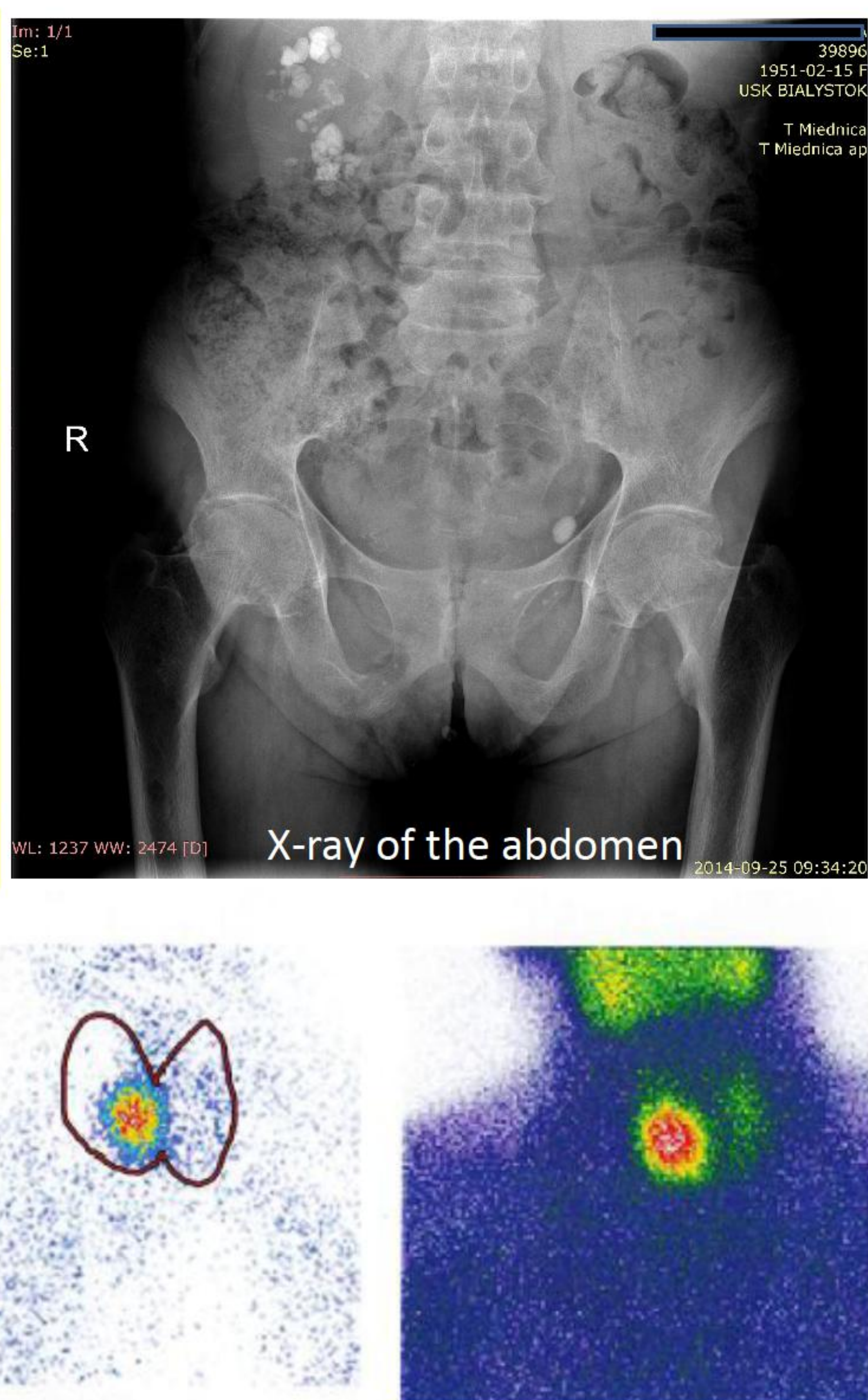

99mTc-MIBI


$\mathrm{BMD}(\mathrm{g} / \mathrm{cm} 2)$

Densitometry Ref: L2-L4 (BMD)

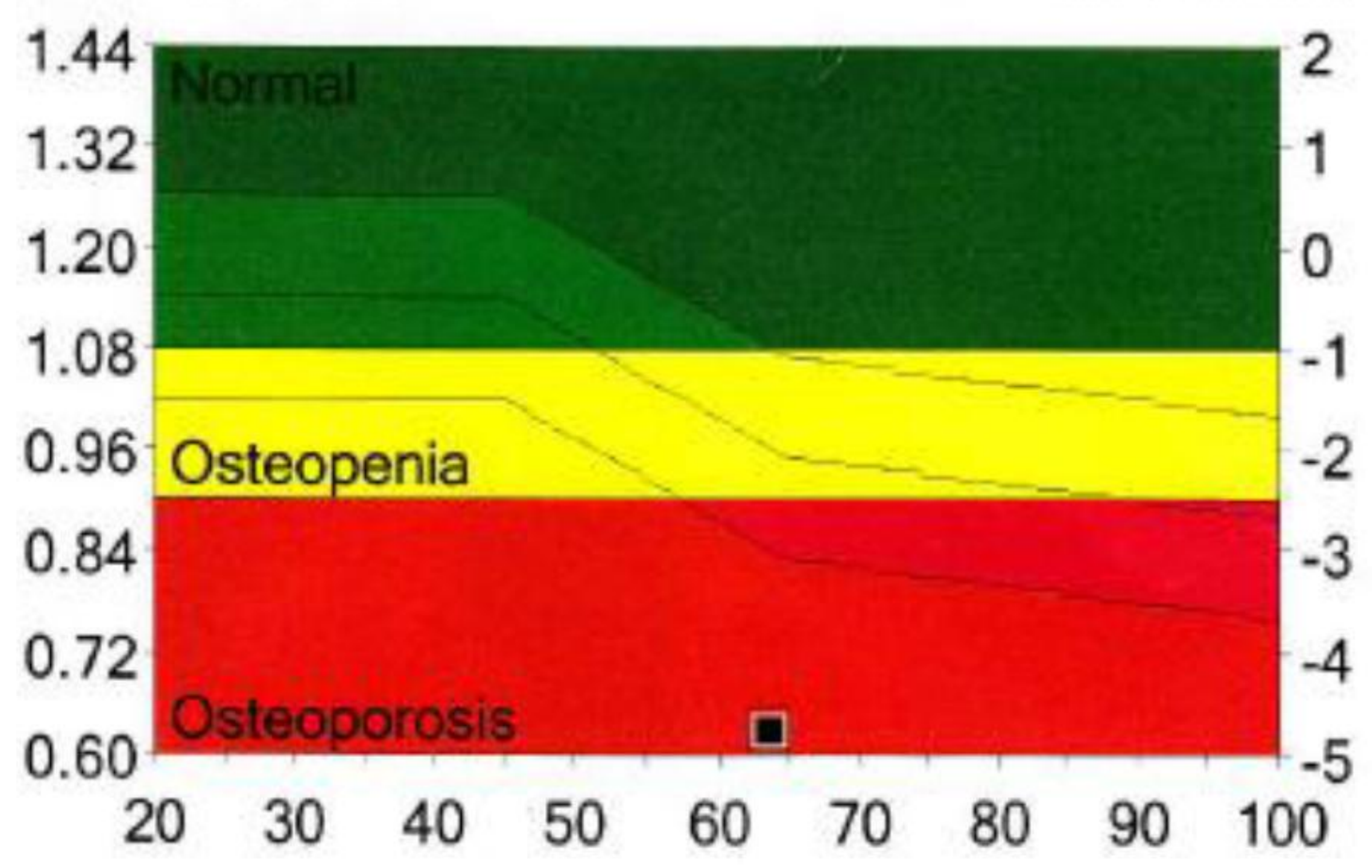

DXA osteodensitometry showed advanced osteoporosis (-4,8 SD lumbar and -3,6 SD femoral neck T-score).

During the parathyreoidectomy rapid decrease of serum PTH was observed (to $150 \mathrm{pg} / \mathrm{ml}$ ). Two months postoperatively patient developed hypocalcaemia $(1,93 \mathrm{mmol} / \mathrm{l})$ and again high level of PTH $(946 \mathrm{pg} / \mathrm{ml})$. The diagnosis of hungry bone syndrome was made.

The treatment with vitamin D, calcium supplementation and alendronate sodium was started, which resulted in a gradual decrease in PTH and normalization of serum calcium.

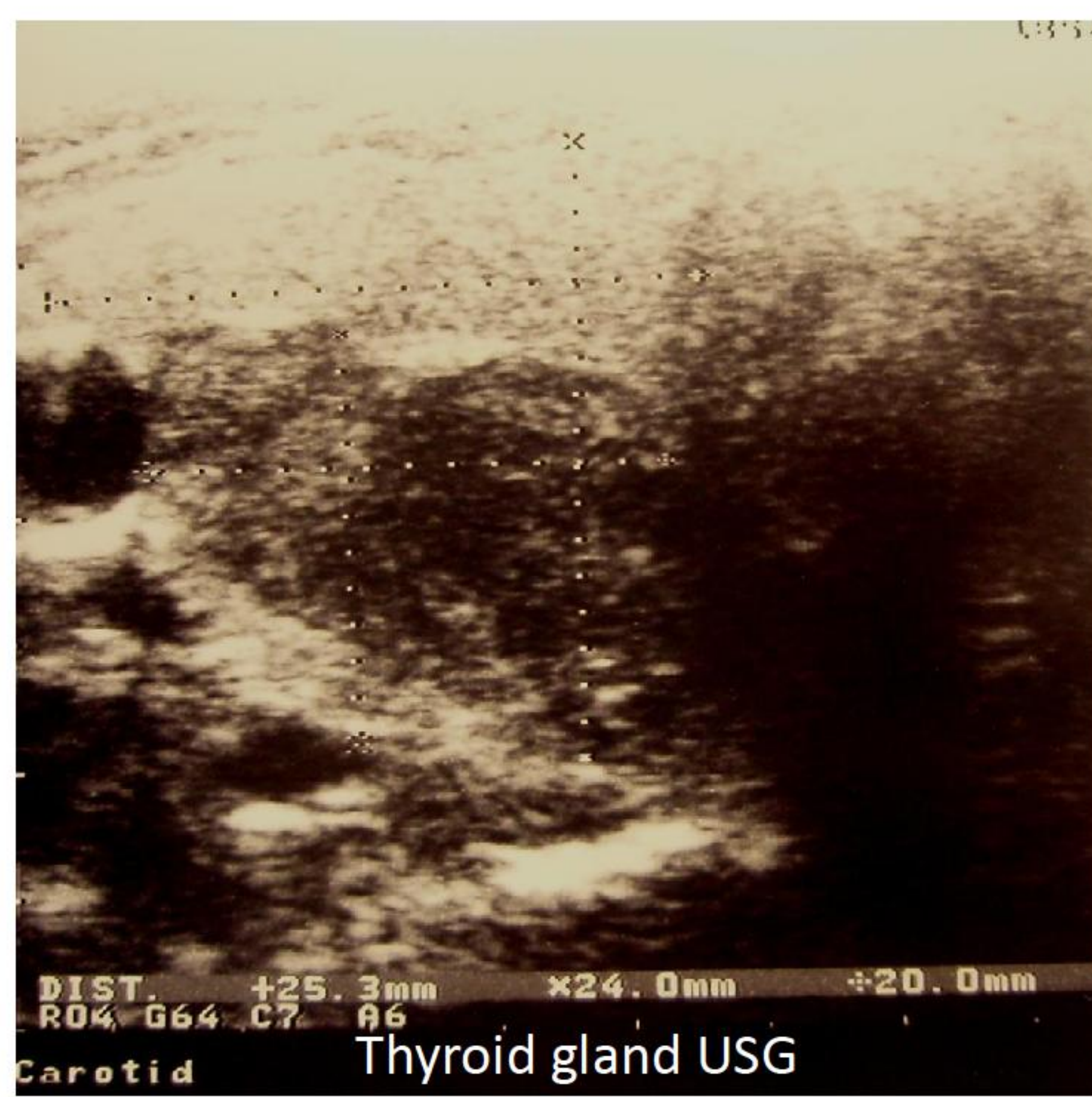

Neck ultrasonography demonstrated multinodular goitre (thyroid function tests were normal). The biggest nodule was found in the right thyroid lobe, it was hypoechogenic and had $20 \times 16 \times 24 \mathrm{~mm}$ diameter.

99mTc-sestamibi scintigraphy detected abnormal lower right parathyroid gland.

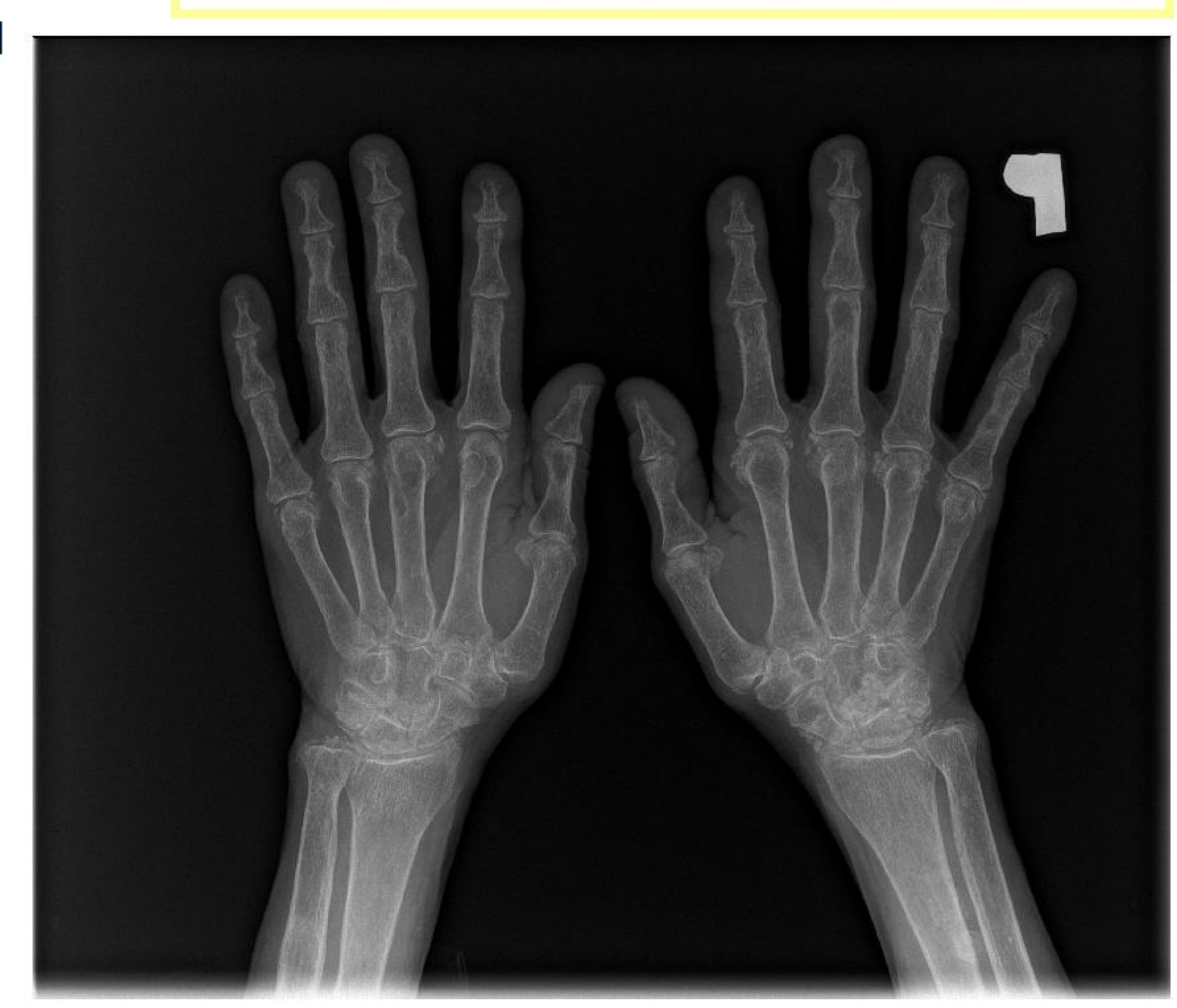

X-ray of the hands

- decreased bone density

- subperiosteal resorption

- focal bone defects within phalanges and metacarpal bones

- osteolysis of ungual tuberosity

- destruction of styloid processes

- metacarpophalangeal joint space narrowing

- calcifications near the heads of metacarpal bones

In each case of nephrolithiasis the probability of hyperparathyroidism should be checked, otherwise it can lead to irreparable damages of human organism. 